\title{
COMUNICAÇÃo
}

\section{VARIANTES AO MÉTODO DE KATO-KATZ UTILIZADAS NO DIAGNÓSTICO DA ESQUISTOSSOMOSE EXPERIMENTAL}

\author{
José Maurício A. Camello, João Inácio Irmão e Paulo de Almeida
}

A importância do método de Kato-Katz na pesquisa qualitativa e quantitativa de helmintos intestinais é reconhecida pelos pesquisadores de todo o Brasil. No entanto, o estudo de variantes ao método tem procurado detectar procedimentos que possam melhorar a visualização, conservação e contagem de ovos do $S$. mansoni.

Pinto e cols ${ }^{2}$ avaliam uma variante ao método de Kato-Katz em que empregam a coloração pela fucsina de Ziehl a fim de melhorar a visualização dos ovos do $S$. mansoni como também a contagem ea viabilidade dos mesmos. A variante, no entanto, não correspondeu às expectativas dos autores no que se refere à contagem (menor do que Kato-Katz normal) e à avaliação da viabilidade dos ovos.

Em nosso trabalho, empregamos a técnica de Kato-Katz (K-K) e outros procedimentos como, Kato-Katz (K-K,sVM) sem verde malaquita, KatoKatz (K-K,AP) com ácido pícrico em substituição ao verde malaquita, Kato-Katz, TAF) com solução de trietanolamina substituindo a glicerina a $50 \%$ e verde malaquita, na identificação de ovos de $S$. mansoni de amostras fecais de 18 camundongos Swiss infectados previamente com cercárias da cepa SLM do parasito. Utilizamos a técnica de Kato-Katz segundo Katz e cols ${ }^{1}$. Empregamos além do verde malaquita a $3 \%$, as soluçōes de ácido pícrico $0,04 \mathrm{M}$ e o TAF $(20 \mathrm{ml}$ de trietanolamina $+10 \mathrm{ml}$ de formol e água destilada q.s.p.100 ml). A solução de trietanolamina tem sido usada na conservação de helmintos intestinais adultos, para demonstrações em aulas práticas. No procedimento $\mathrm{K}-\mathrm{K}, \mathrm{sVM}$ não adicionamos $1 \mathrm{ml}$ do verde malaquita a $3 \%$ na glicerina diluída, no $\mathrm{K}$ $\mathrm{K}, \mathrm{AP}$ a solução saturada de ácido pícrico substitui quantitativamente o verde malaquita a $3 \% . \mathrm{Na}$ variante $K-K, T A F$ a solução de tritanolamina substitui por completo a glicerina diluída e o verde

\footnotetext{
Disciplina de Parasitologia, Departamento de Medicina Tropical, Universidade Federal de Pernambuco, Recife, PE. Endereço para correspondência: Prof. José Maurício A. Camello. Estrada Real do Poço, 374, Casa Forte, 52061-200 Recife, PE.

Recebido para publicação em 12/11/91.
}

malaquita. Foram preparadas 48 lâminas para cada procedimento, posteriormente examinadas por nós.

Identificamos 4613 ovos de S. mansoni nas 192 lâminas examinadas, obtendo os seguintes resultados: K-K 1325 (28,7\%) ovos, K-K,sVM $1283(27,8 \%)$ ovos, K-K, AP 1491 (32,3\%) e K-K,TAF 514 (11,2\%) ovos (Tabela 1 ).

As mensurações dos ovos de $S$. mansoni pelos procedimentos $\mathrm{K}-\mathrm{K}, \mathrm{K}-\mathrm{K}, \mathrm{sVM}$ e $\mathrm{K}-\mathrm{K}, \mathrm{AP}$ não apresentam diferenças significativas, enquanto o $\mathrm{K}$ $\mathrm{K}, \mathrm{TAF}$ demonstra alteração no comprimento e largura em relação aos anteriormente citados (Tabela 2).

Os achados da micrometria referem-se a valores médios.

A observação dos ovos submetidos ao procedimento $\mathrm{K}-\mathrm{K}, \mathrm{TAF}$ demonstrou uma solução de continuidade na porção mediana da cutícula, transversal ao maior diâmetro dos mesmos, o que não ocorreu nos demais procedimentos. Os procedimentos destacam o espículo que apresenta uma coloração amarelada porém, não acontece o mesmo com o miracídio que é pouco visível em todos. No decorrer do experimento percebemos que algumas lâminas submetidas ao Kato-Katz, sem verde malaquita, apresentaram desenvolvimento de fungos anemófilos.

Os elementos coletados nos permitem concluir que na amostra, ocorreu discreta superioridade do procedimento Kato-Katz com ácido pícrico em relação aos demais, no que se refere ao número de ovos identificados.

\section{REFERÊNCIAS BIBLIOGRÁFICAS}

1. Katz N, Chaves A, Pellegrino J. A simple device for quantitative stool tchick-smear technique in schistosomiasis mansoni. Revista do Instituto de Medicina Tropical de São Paulo 14:397-400, 1972.

2. Pinto PLS, Campos R, Amato Neto V, Moreira AAB, Castilho VLP, Gomes AEC. Estudo de uma Variante do Método de Kato-Katz, para avaliação quantitativa de ovos de Schistosoma mansoni nas fezes, baseada no uso da coloração pela fucsina. Revista Brasileira de Patologia Clínica 18:31-33, 1982. 
Comunicação. Camello JMA, Irmão JI, Almeida P. Variantes ao método de Kato-Katz utilizados no diagnóstico da esquistossomose experimental. Revista da Sociedade Brasileira de Medicina Tropical 25:79-80, jan-mar, 1992.

Tabela 1 - Demonstrativo da contagem de ovos de S. mansoni pelos procedimentos empregados $e$ periodos coletados. Recife/1991.

\begin{tabular}{|c|c|c|c|c|c|c|}
\hline \multirow{2}{*}{ Semanas } & & \multicolumn{4}{|c|}{ Métodos } & \multirow{2}{*}{$\begin{array}{c}\text { Total } \\
\text { de ovos }\end{array}$} \\
\hline & & $\mathrm{K}-\mathrm{K}$ & $\mathrm{K}-\mathrm{K}, \mathrm{sVM}$ & $\mathrm{K}-\mathrm{K}, \mathrm{AP}$ & $\mathrm{K}-\mathrm{K}, \mathrm{TAF}$ & \\
\hline $1 a$. & & 383 & 384 & 401 & 89 & 1257 \\
\hline $2 a$. & & 478 & 434 & 549 & 216 & 1677 \\
\hline $3 a$. & & 212 & 232 & 245 & 94 & 783 \\
\hline 4a. & & 136 & 122 & 152 & 64 & 474 \\
\hline $5 a$. & & $116^{\circ}$ & 111 & 144 & 51 & 422 \\
\hline \multirow[t]{2}{*}{ Total } & $\mathbf{n}$ & 1325 & 1283 & 1491 & 514 & 4613 \\
\hline & $\%$ & 28,7 & 27,8 & 32,3 & 11,2 & 100,0 \\
\hline
\end{tabular}

Tabela 2 - Avaliação morfométrica dos ovos de S. mansoni pelos procedimentos empregados. Recifel 1991.

Dimensões $/ \mu \mathrm{m}$

\begin{tabular}{c}
\multicolumn{3}{c}{ Métodos } \\
K-K
\end{tabular}

Comprimento

138,1

138,1

134,9

141,4

Largura

68,2

60,1

65,0

79,6 